\title{
CONSERVADORISMO EM CINCO PAÍSES DA AMÉRICA DO SUL*
}

\author{
CONSERVATISM IN FIVE SOUTH-AMERICAN COUNTRIES
}

\section{FÁBIO MORAES DA COSTA}

Professor Doutor da Fundação Instituto Capixaba de Pesquisas em Contabilidade, Economia e

Finanças - ES

E-mail: fabio@fucape.br

\author{
ALEXSANDRO BROEDEL LOPES \\ Professor Livre-Docente do Departamento \\ de Contabilidade e Atuária da Faculdade de \\ Economia, Administração e Contabilidade da \\ Universidade de São Paulo - SP \\ Pesquisador do CNPq \\ E-mail: broedel@usp.br
}

\author{
ALESSANDRA CRISTINA DE OLIVEIRA COSTA \\ Mestre em Ciências Contábeis pela Fundação \\ Instituto Capixaba de Pesquisas em \\ Contabilidade, Economia e Finanças - ES \\ E-mail: alecosta@arcelor.com.br
}

\section{RESUMO}

Este estudo foi desenvolvido objetivando a avaliação de como o lucro contábil incorpora o retorno das ações de empresas argentinas, brasileiras, colombianas, peruanas e venezuelanas. Para tanto, o grau de assimetria de reconhecimento de boas e más notícias foi analisado utilizando-se o modelo de Basu (1997). Os resultados indicam uma baixa relação entre lucro corrente e retorno corrente. Tal fato pode ser explicado pela relação entre modelos de governança corporativa e seu relacionamento com a relevância da informação contábil, levando-se em conta seu ambiente institucional. Ressalte-se que foi observado um reconhecimento assimétrico entre más e boas notícias, evidenciando um certo grau de conservadorismo no lucro contábil. Este trabalho contribui para reduzir a lacuna existente na literatura internacional com relação ao papel da contabilidade em países em desenvolvimento.

Palavras-chave: Conservadorismo; Contabilidade Internacional; Modelo de Basu.

\begin{abstract}
This study was developed to evaluate how earnings reported in the financial statements incorporate stock returns of public companies from Argentina, Brazil, Colombia, Peru and Venezuela. Thus, the level of asymmetry on recognition of good and bad news was analyzed applying the Basu model (1997). Results indicate a low relationship between current earnings and current stock returns. This fact can be explained by the relationship between corporate governance models and their relationship with the value-relevance of accounting information taking into account the institutional environment. It must be highlighted that an asymmetric recognition was observed between good and bad news, indicating a certain level of conservatism on accounting earnings. This work contributes to reduce the existing gap on international literature regarding the role of accounting in developing countries.
\end{abstract}

Keywords: Conservatism; International Accounting; Basu Model. 


\section{INTRODUÇÃO}

Segundo Hendriksen e Breda (1999, p. 217), uma das características do lucro é a sua provável capacidade de predição. Os investidores podem estar interessados no lucro de hoje para a predição de lucros e dividendos futuros, assim como para a predição do preço das ações. Sendo assim, "um aspecto crucial da pesquisa sobre o impacto de lucros contábeis no mercado de capitais é a determinação do conteúdo informacional dos dados de lucro" (op. cit., p. 206), tendo sido o conteúdo informacional por eles identificado como sendo a diferença entre o número que era esperado e o número real.

Nesse contexto, uma característica importante do lucro contábil é a de que ele seja "oportuno" em termos de fornecimento de informações. Podese definir o termo oportuno de duas maneiras. $\mathrm{Na}$ primeira, o lucro será oportuno se estiver disponível antes de perder sua capacidade de influenciar decisões; não adiantaria apurar e divulgar o lucro do ano, seis meses após o encerramento do ano fiscal, pois esse já terá perdido sua capacidade de auxiliar a tomada de decisões. Na segunda, conforme definido por Ball et al. (1999, p. 01), a oportunidade do lucro refere-se à extensão com que ele incorpora o retorno da ação no período, sendo essa incorporação influenciada pelo ambiente institucional das empresas, ou seja, a estrutura legal do país, a estrutura acionária das empresas, a regulamentação contábil, a força da profissão contábil, a influência da legislação fiscal, as fontes de financiamentos, entre outros fatores.

A oportunidade da informação contábil, no reconhecimento do retorno da ação, está relacionada a um dos princípios básicos aplicado na Contabilidade, o conservadorismo, que, segundo Basu (1997, p. 7), está ligado à tendência da Contabilidade para exigir um maior grau de verificação das boas notícias para reconhecê-las como lucro, do que das más notícias para reconhecê-las como prejuízo.

Por outro lado, na busca de entender e identificar o papel da informação contábil em diferentes países ou cenários, estudos empíricos foram desenvolvidos visando comparar a informação contábil entre países, como, por exemplo: Alford et al. (1993), Ball et al. (1999), Ali e Hwang (2000), Giner e Rees (2001). Nesses trabalhos, os autores concluíram que a relevância da informação contábil, o conteúdo informacional e a oportunidade do lucro contábil variam entre os países estudados, sendo influenciado por vários fatores como: fontes de financiamento, responsabilidade pelo estabelecimento de normas, influência da legislação fiscal, nível de gastos com auditoria externa, nível de evidenciação das informações, estrutura acionária, entre outros.

Trabalhos, como os citados anteriormente, são relevantes devido ao atual contexto de organização dos países em blocos econômicos e os movimentos mundiais em torno da convergência de normas contábeis. Dessa forma, estudos que se proponham a analisar e identificar as semelhanças e as diferenças existentes entre os países, contribuindo para o entendimento do seu ambiente institucional, tornamse necessários, sendo úteis para orientar mudanças demandadas pela nova realidade mundial.

Especificamente, na América do Sul, essa pode ser dividida em dois blocos econômicos: a) Comunidade Andina: formada em maio de 1969, com a assinatura do "Acordo de Cartagena" e atualmente composta pelos seguintes países: Bolívia, Colômbia, Equador, Peru e Venezuela e b) Mercado Comum do Sul - Mercosul: constituído por meio do "Tratado de Assunção", em 1991, é formado por Argentina, Brasil, Paraguai e Uruguai.

Com o objetivo de aproximar os dois blocos econômicos da região, foi assinado, em abril de 1998, um acordo para a criação de uma região de livre comércio entre a Comunidade Andina e o Mercosul.

Diante dos esforços de redução das barreiras entre os países, este trabalho propõe-se a analisar como o lucro contábil incorpora o retorno econômico ${ }^{1}$ do período, ou seja, a oportunidade do lucro contábil no reconhecimento de lucros e prejuízos ou boas e más notícias em cinco países da América do Sul, membros ou da Comunidade Andina ou do Mercosul, em um ambiente em que um dos pressupostos básicos da Contabilidade é do conservadorismo.

Ademais, avalia-se o conteúdo informacional dos números contábeis para o mercado de capitais, agregado ao conceito teórico de conservadorismo; isso em cinco países de uma mesma região - a América do Sul - em um momento de união dos países em torno de blocos econômicos, da expansão de discussões sobre convergência contábil e do aumento das exigências de mecanismos de governança corporativa ${ }^{2}$. Verifica-se que ainda há carência significativa para estudos empíricos voltados para

1 Retorno econômico refere-se à variação do preço da ação da empresa, negociada em Bolsa de Valores, no período $\left(\mathrm{P}_{\mathrm{t}}-\mathrm{P}_{\mathrm{t}-1}\right)$ ajustada pelos dividendos.

2 Segundo o IBGC - Instituto Brasileiro de Governança Corporativa, o termo Governança Corporativa refere-se às "práticas e os relacionamentos entre os Acionistas/Cotistas, Conselho de Administração, Diretoria, Auditoria Independente e Conselho Fiscal, com a finalidade de otimizar o desempenho da empresa e facilitar o acesso ao capital". Disponível em http://www.ibgc.org.br. 
países em desenvolvimento que tenham como objetivo identificar o conteúdo informacional dos números contábeis para o mercado de capitais.

Diante da importância do conteúdo informacional dos lucros e da oportunidade da informação contábil, levanta-se o seguinte questionamento: Como o lucro contábil incorpora o retorno econômico na Argentina, no Brasil, na Colômbia, no Peru e na Venezuela e como o Conservadorismo (assimetria no reconhecimento de boas e más notícias) vem sendo utilizado nesse processo de reconhecimento do retorno econômico pelo lucro contábil?

Para o estudo, foram selecionados os seguintes países: Argentina e Brasil - membros do Mercosul, Colômbia, Peru e Venezuela - membros da Comunidade Andina, pois são os países com maior número de habitantes e maior Produto Interno Bruto dentro de seus respectivos blocos, como pode ser verificado nas Tabelas 1 e 2. O Chile, por participar de forma parcial no Mercosul, não foi analisado na amostra.

Tabela 1 - População e P.I.B. dos países da Comunidade Andina

\begin{tabular}{c|c|c|c|c}
\hline Comunidade Andina & \multicolumn{2}{|c|}{ Habitantes } & \multicolumn{2}{c}{ Produto Interno Bruto } \\
\hline Dados de 2002 & (milhões) & $\%$ & (US\$ bi) & $3 \%$ \\
\hline Bolívia & 8,7 & $7 \%$ & 7,8 & $32 \%$ \\
\hline Colômbia & 43,8 & $37 \%$ & 81,5 & $10 \%$ \\
\hline Equador & 13,1 & $11 \%$ & 24,4 & $22 \%$ \\
\hline Peru & 26,5 & $23 \%$ & 56,9 & $33 \%$ \\
\hline Venezuela & 25,0 & $22 \%$ & 84,7 & \\
\hline Total & $\mathbf{1 1 7 , 1}$ & & $\mathbf{2 5 5 , 3}$ & \\
\hline
\end{tabular}

Fonte: http://www.comunidadandina.org (acesso em 11.06.2003)

Tabela 2 - População e P.I.B. dos países do Mercosul

\begin{tabular}{c|c|c|c|c}
\hline Mercosul & \multicolumn{2}{|c|}{ Habitantes } & \multicolumn{2}{c}{ Produto Interno Bruto } \\
\hline Dados de 2001 & (milhões) & $\%$ & (US\$ bi) & \% \\
\hline Argentina & 36,2 & $17 \%$ & 268,7 & $63 \%$ \\
\hline Brasil & 172,4 & $78 \%$ & 510,4 & $1 \%$ \\
\hline Paraguai & 5,6 & $3 \%$ & 7,2 & $2 \%$ \\
\hline Uruguai & 3,3 & $2 \%$ & $\mathbf{8 0 5 , 0}$ &
\end{tabular}

Fonte: http://www.mercosul.org.uy (acesso em 11.06.2003)

Para responder à questão de pesquisa, os objetivos deste trabalho consistem em: (1) analisar a oportunidade da informação contábil (reconhecimento do retorno econômico pelo lucro contábil) na Argentina, Brasil, Colômbia, Peru e Venezuela; (2) verificar se existem diferenças na aplicação do conservadorismo (reconhecimento contábil dos resultados econômicos negativos e positivos) na Argentina, Brasil, Colômbia, Peru e Venezuela.

A abordagem metodológica utilizada no presente trabalho é a positiva, que segundo Watts e Zimmerman (1986, p. 14):

pode promover aos que devem tomar decisões sobre políticas contábeis (gerentes corporativos, contadores certificados, credores, in- vestidores, analistas de mercado, reguladores) predições sobre, e explicações para, as conseqüências destas decisões. Um importante teste para a teoria contábil consiste em avaliar quão útil ela é. (tradução livre).

Em relação aos procedimentos técnicos, a pesquisa desenvolvida enquadra-se como ex post facto, pois a experimentação é feita após a ocorrência dos fatos, não havendo controle do pesquisador sobre as variáveis (GIL: 1991, p. 45).

Espera-se que os resultados contribuam para o entendimento de como se dá o reconhecimento do retorno econômico pelo lucro contábil nos cinco países estudados e como é utilizado o conceito de 
Conservadorismo no reconhecimento de boas ou más notícias pelo lucro contábil. Dessa forma, reduz-se a lacuna existente na literatura internacional com relação ao papel da Contabilidade em países em desenvolvimento.

Este trabalho não tem como foco a comparação de normas contábeis de diferentes países, tendo como abordagem principal a avaliação e análise dos efeitos de sua aplicação. A simples análise da norma pode levar a erros de interpretação, sabendo-se que regras e normas formais podem divergir da prática contábil. Dessa forma, este trabalho se propõe a analisar a oportunidade da informação contábil e o conceito de Conservadorismo nos países estudados por meio da análise do lucro contábil que incorpora não só as normas formais, como as práticas contábeis dos países estudados.

O trabalho foi organizado da seguinte forma: a seção 2 consiste na apresentação e discussão do referencial teórico, por meio de revisão bibliográfica, que dará sustentação à questão formulada. Buscar-se-á identificar em que estágio de desenvolvimento se encontra o assunto em questão, em âmbito nacional e internacional; na seção 3 , será apresentado o modelo utilizado, a técnica de coleta de dados e suas respectivas estatísticas descritivas e resultados da aplicação do modelo em empresas de cada um dos cinco países; na quarta e última seção, apresenta-se a conclusão e sugestões para pesquisas futuras.

\section{REFERENCIAL TEÓRICO}

Trabalhos, como o de Alford et al. (1993) e Ali e Hwang (2000), identificaram que diferenças no ambiente institucional dos países podem gerar diferenças na relevância da informação contábil. Dentro dessa ótica, no próximo item alguns fatores que influenciam o ambiente institucional dos países são apresentados, procurando identificar como essas características se apresentam nos cinco países estudados. O objetivo é entender como esses países estão estruturados, para, na seção 3 buscar-se uma relação entre os resultados encontrados e seu ambiente institucional, pois as características dos países influenciam as normas e práticas contábeis aplicadas nas empresas.

Serão discutidas, a seguir, as principais características citadas por Ball et al. (1999), Ali e Hwang (2000), Giner e Rees (2001) e Lopes (2001), como sendo relevantes para entendermos o ambiente institucional dos países:

a) Estrutura legal do país: Embora cada país possua sua estrutura legal, essas estruturas possuem características similares, - que possibilita agrupá-las em grandes modelos ou famílias de direito. $\mathrm{O}$ direito pode ser classificado em duas famílias relevantes para a Contabilidade: a família Code-law ou Direito Romano e a família Common-law ou Direito Consuetudinário. Os países com estrutura Code-law apresentam características, tais como: concentração de poder nas mãos de poucos acionistas; a Contabilidade se confunde com a área tributária; a Contabilidade é regulamentada diretamente pelo governo; há menor demanda por informações públicas. De outro modo, os países com estrutura Common-law ou de Direito Consuetudinário têm estrutura geral de organização menos regulamentada que as Code-law, mercado de capitais bem desenvolvido, profissão contábil auto-regulamentada, distinção entre a Contabilidade e a área tributária, e a Contabilidade fora da esfera governamental ${ }^{3}$.

b) Regulamentação Contábil: É importante identificar em um país, quem são os responsáveis pela regulamentação das práticas contábeis, se é o governo ou se são órgãos privados formados por profissionais da área e do mercado. Nos países de modelo Code-law, normalmente, a regulamentação contábil é exercida pelo governo. Nos de modelo Common-law, a regulamentação está sob a responsabilidade de órgãos privados, mesmo quando os órgãos governamentais possuem autoridade para a regulamentação contábil.

c) Estrutura acionária: Nesse item, pode-se classificar os países utilizando o modelo shareholder ou o modelo stakeholder. No modelo shareholder, o mercado de capitais é mais desenvolvido que no stakeholder e possui uma base acionária dispersa, em que acionistas individuais raramente possuem controle sobre a empresa. No modelo stakeholder, o controle das empresas está concentrado nas mãos de poucos acionis-

3 Autores como La Porta et al. (1998; 2000), Ball et al. (2000) e Weffort (2003) promovem uma discussão mais aprofundada sobre as principais diferenças entre características de países code-law e common-law. 
tas. Lopes (2001, p. 125) resume que o impacto destes dois sistemas na Contabilidade é enorme, pois no modelo shareholder, a Contabilidade possui o papel de levar informações e sinais ao mercado, enquanto no modelo stakeholder os acionistas estão dentro da empresa.

d) Força da profissão contábil: O prestígio e a importância da profissão contábil pode influenciar a qualidade da Contabilidade praticada nesses países, assim como influenciar na definição de normas, padrões e práticas contábeis.

e) Impacto da legislação tributária: O grau de influência da legislação tributária na
Contabilidade é fator de distinção entre os países.

f) Fontes de financiamento: As fontes de financiamento das empresas podem influenciar diretamente no modelo de evidenciação das informações contábeis. Países, onde as fontes de financiamentos são o mercado acionário, tendem a possuir modelo de evidenciação mais claros e completos que países onde as fontes de financiamentos são os credores (Bancos).

Nesse contexto, na Tabela 3, os cinco países da América do Sul são classificados de acordo com os itens descritos anteriormente:

Tabela 3 - Ambiente institucional de cinco países da América do Sul

\begin{tabular}{l|c|c|c|c|c|c}
\multicolumn{1}{c|}{ País } & $\begin{array}{c}\text { Regime } \\
\text { Jurídico }\end{array}$ & $\begin{array}{c}\text { Regulamentação } \\
\text { Contábil }\end{array}$ & $\begin{array}{c}\text { Estrutura } \\
\text { Acionária }\end{array}$ & $\begin{array}{c}\text { Força da } \\
\text { Profissão } \\
\text { Contábil }\end{array}$ & $\begin{array}{c}\text { Impacto da } \\
\text { Legislação } \\
\text { Tributária }\end{array}$ & $\begin{array}{c}\text { Fontes de } \\
\text { Financiamento }\end{array}$ \\
\hline Argentina & Code-law & Governo & $\begin{array}{c}\text { Stakeholders' } \\
\text { System }\end{array}$ & Pequena & Alto \\
\hline Brasil & Code-law & Governo & $\begin{array}{c}\text { Stakeholders' } \\
\text { System }\end{array}$ & Pequena & Bancária \\
\hline Colômbia & Code-law & Governo & $\begin{array}{c}\text { Stakeholders' } \\
\text { System }\end{array}$ & Pequena & Alto \\
\hline Peru & Code-law & Governo & $\begin{array}{c}\text { Stakeholders' } \\
\text { System }\end{array}$ & Pequena & Alto \\
\hline Venezuela & Code-law & $\begin{array}{c}\text { Órgão de Classe } \\
\text { e Governo }\end{array}$ & $\begin{array}{c}\text { Stakeholders' } \\
\text { System }\end{array}$ & Pequena & Bancária \\
\hline
\end{tabular}

Fontes: Lopes (2001); Lisboa (2000); Amenábar (2001); Pricewaterhouse (1993; 1994; 1997; 2001).

Dessa forma, a análise da Tabela 3 permite verificar que os países da América do Sul estudados possuem um ambiente institucional similar, em que apenas a Venezuela possui diferentes características com relação à regulamentação contábil e à força da profissão contábil. Segundo a PriceWaterhouse (1997, p. 12), as normas contábeis da Venezuela aplicáveis às empresas não financeiras e indústrias são determinadas principalmente pela Federação de Colégios de Contadores Públicos da Venezuela (FCCPV). As empresas com ações listadas em Bolsa estão sujeitas a Comissão de Valores Nacional (National Securities Commission-CNV). Caso ocorram situações em que nenhum dos institutos tenha emitido pronunciamento, deve-se utilizar as normas Mexicanas e em caso de sua inexistência recorre-se às normas Norte-americanas.

\subsection{A Contabilidade e o Mercado de Capitais}

Muitos atribuem ao estudo publicado por Ball e Brown (1968) o início da área de pesquisas empíricas abordando a Contabilidade e o mercado de capitais (WATTS e ZIMMERMAN, 1986, p. 37). Os autores investigaram empiricamente a relação entre o lucro contábil e o preço das ações, e, além disso, se o lucro contábil simplesmente refletia fatores já incorporados ao preço das ações, ou se a divulgação do lucro possuía conteúdo informacional para o mercado de capitais (BALL e BROWN: 1968).

Autores como Lopes (2001, p. 88) destacam outros estudos que surgiram a partir de Ball e Brown (1968), entre eles o de Beaver e Demski (1979), no qual os autores concluíram que "os mesmos fatores 
que influenciam o comportamento do resultado do exercício impactam os preços".

Portella (1995, p. 24) cita os estudos de Beaver et al. (1980) e Kothari e Sloan (1992), nos quais os autores concluíram que "na verdade, os preços das ações guiam os lucros contábeis e não o contrário porque os preços das ações refletem informações, na maior parte, recebidas de outras fontes que não as contábeis". Adicionalmente, elas refletem as informações mais rapidamente que o lucro.

Lopes (2001, p. 88) comenta, ainda, o estudo realizado por Beaver (1968), que analisou o comportamento dos preços e do volume negociado, nas semanas próximas da divulgação de informações contábeis. Segundo Lopes, "este estudo demonstrou que tanto o preço como o volume negociado reagem fortemente à informação contábil, principalmente, na semana dos anúncios".

No entanto, de acordo com Hendriksen e Breda (1999, p. 206):

a correlação entre lucro e preço é imperfeita.

Parte do motivo para falta de correlação perfeita está no fato de que os preços captam o impacto de um conjunto de informações muito mais amplo do que o representado apenas por lucros contábeis. [...]. Um outro motivo para a falta de correlação perfeita é o fato de que algumas flutuações dos lucros contábeis resultam de mudanças de regras contábeis, sem qualquer implicação econômica imediata.

Lopes (2001, p. 90) resume que:

uma revisão geral da literatura nos leva a concluir que o lucro contábil é relevante, mas possui baixo poder explicativo. A relevância dos resultados contábeis também depende de condições gerais de funcionamento do mercado e do nível de eficiência do mesmo.

Devido ao importante papel desempenhado pelo lucro, é justificável que haja uma preocupação com a sua qualidade, com os critérios utilizados para a sua formação e principalmente com a sua consistência, embora uma definição precisa do termo "qualidade dos lucros" ainda não tenha sido alcançada.

Essa preocupação tem feito com que muitos pesquisadores desenvolvam trabalhos empíricos, para testar a qualidade do lucro gerado pelas empresas ou, segundo Chan et al. (2001, p. 1), "a extensão com a qual os lucros reportados refletem os fundamentos operacionais", sendo o regime de Competência um dos pressupostos básicos da Contabilidade, no qual,

os efeitos das transações e outros eventos são conhecidos quando ocorrem (e não quando o numerário ou seu equivalente é recebido ou pago) e são lançados nos registros contábeis e reportados nas demonstrações financeiras dos períodos a que pertencem (IASC, ed. anuais, p. 547).

Nesse contexto, a Contabilidade "tem a responsabilidade de atribuir parcelas, mesmo que apenas aproximadas, de seu resultado total, aos vários períodos" (IUDÍCIBUS, 2000, p. 49). Para Hendriksen e Breda (1999, p. 105), "a informação a respeito de uma dada empresa deve ser apresentada, de modo a permitir, que os usuários de relatórios financeiros façam seus próprios julgamentos quanto ao futuro da organização". Portanto, pode-se perceber que é grande a responsabilidade da Contabilidade, no processo de atribuir valores estimados para a apuração do lucro.

Nesse ambiente, a mensuração contábil exigirá a utilização de estimativas de valores futuros incertos. Por exemplo, a depreciação, é na verdade, a estimativa da contribuição do imobilizado para a formação do custo de produção do período. O método de depreciação utilizado deve ser o que melhor mensure essa contribuição.

A utilização de estimativas gera incerteza quanto ao seu valor correto, sendo palco para mais um importante tema de discussão na Contabilidade - Relevância x Confiabilidade do valor estimado utilizado. Richardson et al. (2001) comentam que, se por um lado as informações oriundas da utilização de estimativas ou provisões sobre os futuros benefícios e obrigações financeiras da empresa são consideradas relevantes para os usuários da Contabilidade, por outro lado, são consideradas menos confiáveis, que as informações de recebimentos e pagamentos de caixa. Essa incerteza, com relação à utilização de estimativas, serviu de base para outro conceito contábil - O Conservadorismo, que após o trabalho de Basu (1997) passou a ser visto sob o enfoque do reconhecimento pelo lucro contábil de más notícias mais oportunamente que de boas notícias.

\subsection{Conservadorismo}

O Conservadorismo é um conceito amplamente utilizado na Contabilidade. ludícibus (2000, p. 75) exemplifica o Conservadorismo como "entre duas ou mais alternativas igualmente relevantes, o contador escolherá aquela que apresentar menor valor para o ativo ou para o lucro e/ou maior valor para o passivo".

Para Watts (1993, p. 18), "conservadorismo é um mecanismo no qual estimativas confiáveis são requeridas para que lucros possam ser antecipados. Esta exigência ocorre devido à assimetria in- 
formacional entre a administração e outras partes da empresa".

Basu (1997, p. 33) define Conservadorismo no resultado, como o reconhecimento de más notícias, mais oportunamente que o reconhecimento de boas notícias, em relação a fluxos futuros de caixa.

Pode-se identificar a utilização do Conservadorismo no balanço ou no resultado. Se a Contabilidade utilizasse o conceito de que qualquer mudança nas contas de balanço (ativo e passivo, com exceção dos dividendos e outras transações com acionistas) teria seu reflexo no resultado, que é o conceito de clean surplus accounting (Ohlson, 1995), não haveria distinção entre o Conservadorismo no balanço e o Conservadorismo no resultado, já que a utilização do primeiro sempre geraria reflexo no segundo. Alguns países permitem a utilização de práticas, cujo reflexo não é no resultado e sim contra uma conta de Patrimônio Líquido. Somente para exemplificar, no Brasil, os ajustes de exercícios anteriores são lançados diretamente contra contas de patrimônio líquido, sem transitarem pelo resultado do exercício.

Dessa forma, esse estudo baseia-se no conceito de Conservadorismo, conforme definido por Basu (1997), gerando reflexo no lucro contábil.

Watts $(1993$, p. 2) destaca que um dos papéis da Contabilidade há séculos está ligado à sua utilização nos contratos firmados entre a empresa e terceiros; por exemplo: contratos de compra, venda, empréstimos, entre outros.

No século XIX, com a revolução Industrial, começaram a surgir os especialistas em Contabilidade, que ganharam força, com a aprovação de uma lei que exigia a participação de um contador nos casos de falências (Hendriksen e Breda, 1999, p. 47). Segundo Watts (1993, p. 4), os contadores tinham o papel de reconhecer todas as perdas possíveis, antes de fazerem as distribuições do resultado, evoluindo daí o conceito de Conservadorismo.

Basu $(1997$, p. 9) acrescenta que fatores tais como litígios, processos políticos e regulatórios e impostos têm influenciado o grau de utilização do Conservadorismo nas normas contábeis.

Mais recentemente, os números contábeis passaram a ser utilizados para fornecer informações para o mercado de capitais, um outro grupo que possui contratos com a empresa. Além disso, o incentivo para a utilização do Conservadorismo pode estar ligado ao modelo legal do país. Nos modelos Commonlaw, o mercado de capitais é desenvolvido e o controle acionário é descentralizado; os números contábeis tendem a ser mais relevantes para os tomadores de decisão que no modelo Code-law com mercado de capitais menos desenvolvido e controle acionário cen- tralizado. Dessa forma, haveria maior interesse dos administradores em apresentarem resultados contábeis mais conservadores nos países Common-law que nos países Code-law.

Alguns autores criticam a utilização do Conservadorismo. Entre eles Hendriksen e Breda (1999, p. 106) justificam que:

o Conservadorismo conflita com o objetivo de divulgar toda informação relevante e também com a consistência no sentido de que é uma limitação relevante. Também pode conduzir a uma falta de comparabilidade, porque não há padrões uniformes para sua implantação.

A utilização excessiva do Conservadorismo pode levar à divulgação de informações com falsos sinais para seus usuários.

Para Lopes (2001, p. 93), "a idéia geral do Conservadorismo é de fornecer informações mais confiáveis aos investidores por intermédio de demonstrações que não sejam excessivamente otimistas". Ainda segundo o autor, o Conservadorismo é o reconhecimento assimétrico entre despesas e passivo, ativos e receitas. Do ponto de vista econômico, é o reconhecimento viesado da realidade.

Alguns autores desenvolveram testes empíricos sobre a relação entre o Conservadorismo contábil nos lucros e o mercado de capitais. Na revisão bibliográfica dos trabalhos de Ball, Kothari e Robin (2000), Watts (1993), Lubberink e Huijgen (2000), Pope e Walker (1999) e Penman e Zhang (1999), percebe-se que os autores, em sua maioria, defendem a utilização do Conservadorismo no lucro contábil, com exceção do trabalho de Penman e Zhang (1999), no qual os autores demonstram que a utilização do Conservadorismo pode gerar lucro de baixa qualidade.

Ball, Kothari e Robin (2000) propuseram um estudo sobre o Conservadorismo contábil em diferentes países. Os autores demonstraram que o contexto institucional em que um determinado país está inserido, influencia as propriedades do lucro contábil, gerando com isso, variações no lucro entre os países. As características examinadas foram:

a) Oportunidade (Timeliness): A incorporação do lucro econômico do período corrente pelo lucro contábil, sendo o lucro econômico representado pela mudança no valor de mercado das ações no período.

b) Conservadorismo: A incorporação assimétrica de ganhos e perdas econômicas pelo lucro contábil do período.

Ball, Kothari e Robin (2000) argumentam que a influência política (governo) no estabelecimento de normas contábeis e de execução legal, diminui 
a demanda por informações contábeis oportunas e conservadoras, aumentando a demanda por lucro com baixa volatilidade. Propuseram estudar essa influência política na Contabilidade. Essa influência política, para os autores, é representada por dois sistemas legais com características bem distintas, que são os sistemas Common-law e Code-law.

A governança corporativa em países Codelaw, em que a estrutura acionária utiliza o modelo stakeholder, tende a ser feita com informações privilegiadas (proximidade entre a administração e os usuários das informações), não tendo, portanto, demanda tão grande para divulgação de informações de forma pública, como em países Common-law. Os autores propõem que esse cenário reduz a demanda por números contábeis oportunos em países Code-law. De outra forma, em países Common-law, em que a estrutura acionária predominante é baseada no modelo shareholder, é grande a demanda por informações de forma pública.

Ball, Kothari e Robin (2000) utilizaram em seu estudo o modelo proposto por Basu (1997), no qual duas conclusões merecem ser destacadas: (1) nos países classificados como Code-law, o lucro contábil é mais constante e menos oportuno na incorporação de mudanças correntes no valor de mercado que nos países classificados como Common-law; (2) o lucro contábil é assimetricamente conservador em todos os países, incorporando perdas econômicas mais oportunamente que ganhos, confirmando que o Conservadorismo, definido como o reconhecimento assimétrico de ganhos e perdas econômicas, é uma propriedade universal do lucro contábil ${ }^{4}$.

Segundo Watts (1993, p. 4), "uma das funções do Conservadorismo parece ter estado relacionada com a divisão contratual do retorno da empresa entre seus vários reclamantes", cujo objetivo era assegurar que não haveria distribuição para ninguém, enquanto não fossem pagas todas as obrigações contratuais existentes na empresa, incentivando, dessa forma, o uso do Conservadorismo. Também a regulamentação afeta, tanto direta quanto indiretamente, as divulgações das informações das empresas, já que aumento de passivos, a partir da regulamentação (por exemplo, o registro de passivo atuarial), incentiva tanto os administradores quanto os auditores a serem conservadores, assim como incentiva as leis de responsabilidade dos auditores.

Lubberink e Huijgen (2000), em seu estudo sobre Conservadorismo, investigaram a relação entre Conservadorismo nos lucros e a preocupação da administração da empresa com a sua própria riqueza.
O Conservadorismo nos lucros tem um importante propósito de reduzir a possibilidade de conflito sobre a distribuição dos fluxos de caixa da empresa entre os participantes da sociedade. Segundo os autores, para reduzir a exposição a fatos que possam afetar sua riqueza, os administradores aumentam o nível de Conservadorismo nos lucros, já que, em muitas empresas, a performance da empresa é um fator determinante da riqueza do administrador (op. cit., p. 22).

Lubberink e Huijgen (2000) utilizaram, como base para o trabalho, o modelo proposto por Basu (1997). Os resultados demonstraram que as preferências individuais dos administradores, também, explicam o Conservadorismo nos lucros. O Conservadorismo nos lucros é afetado pela preocupação da administração com a divulgação da performance da empresa. Concluem, ainda, que administradores avessos a risco apresentam lucros mais conservadores que administradores não avessos a risco.

Foram encontradas evidências de aumento de Conservadorismo no lucro ao longo do período investigado. A explicação para esse fato, dada pelos autores, é que os administradores responderão a pressões externas por relatórios mais objetivos ou verificáveis sobre performance da empresa.

Pope e Walker (1999), em seu estudo, compararam o Conservadorismo no reconhecimento de lucros nos Estados Unidos e na Inglaterra. Com base nas idéias propostas por Basu (1997), de que o Conservadorismo contábil pode induzir à assimetria na oportunidade do lucro, em que as "más notícias" são refletidas nos lucros mais rapidamente que as "boas notícias", os autores apresentam um modelo formal no qual a resposta do lucro contábil a mudanças no valor de mercado da empresa varia em função das mudanças estarem relacionadas às boas ou más notícias.

No período estudado, Pope e Walker (1999) observaram que diferenças aparentes no emprego do Conservadorismo entre as empresas americanas e inglesas são sensíveis à inclusão ou exclusão, de acordo com as normas inglesas, de itens extraordinários nos lucros, pois nesse período existia diferença no momento de reconhecimento de certos eventos contábeis entre as empresas. Por exemplo: pelas normas americanas os ganhos e perdas na venda de ativos são registrados como parte do lucro operacional, enquanto para as empresas inglesas, até 1993, era um item extraordinário. Após a reformulação da norma inglesa, essa, aparentemente, tornou-se mais restritiva que as americanas na utilização de itens extraordinários. 
Penman e Zhang (1999), ao contrário dos trabalhos anteriores, nos quais a utilização do Conservadorismo foi vista pelos autores como algo saudável para a contabilidade, procuraram provar empiricamente que o Conservadorismo nas práticas contábeis pode gerar lucro de baixa qualidade. $O$ questionamento feito por eles é se o mercado consegue identificar essa baixa qualidade do lucro, no momento de precificar as ações.

No estudo de Penman e Zhang (1999), a qualidade do lucro está vinculada à visão do analista de mercado que deseja estimar lucros futuros. Assim, o lucro é de boa qualidade, se for um bom indicador para lucros futuros, ou seja, a ênfase é dada na idéia de "lucro sustentável" ao longo do tempo.

Com a utilização dos indicadores de Conservadorismo e de qualidade dos lucros, ${ }^{5}$ Penman e Zhang (1999) diagnosticaram lucros de baixa qualidade, resultado da mudança nos investimentos em um ambiente de práticas contábeis conservadoras. Outra conclusão, à qual chegaram os autores, é a de que, durante o período do estudo, o mercado financeiro não percebe a qualidade dos lucros das empresas com Conservadorismo contábil, o que pode levar à utilização de lucro com baixa sustentabilidade para estimar lucros futuros.

\section{METODOLOGIA}

Conforme apresentado na introdução, este trabalho investiga como o lucro contábil incorpora o retorno econômico nos países estudados, sendo representado pela seguinte questão de pesquisa: Como o lucro contábil incorpora o retorno econômico na Argentina, no Brasil, na Colômbia, no Peru e na Venezuela e como o Conservadorismo (assimetria no reconhecimento de boas e más notícias) vem sendo utilizado nesse processo de reconhecimento do retorno econômico pelo lucro contábil?

Para responder a essa pergunta, será utilizado o modelo de Basu (1997), que propôs, com seu trabaIho, estudar o Conservadorismo contábil sob a perspectiva do reconhecimento de boas e más notícias pelo lucro contábil, ou seja, uma outra perspectiva que não a tradicional regra de escolher entre as opções disponíveis a que não antecipe os lucros e antecipe os prejuízos. Basu (1997, p. 33) caracteriza o Conservadorismo contábil como: "o reconhecimento no resultado mais oportunamente para más notícias relacionadas a fluxos de caixa futuros do para boas notícias. Em mercados eficientes, o retorno das ações reflete simetricamente e rapidamente todas as notícias disponíveis publicamente." (tradução livre).

Será utilizada a especificação abaixo, que permitirá analisar se o lucro contábil incorpora, significativamente, o retorno econômico nos países estudados:

$$
\frac{L u c_{i t}}{P_{t-1}}=\alpha_{0}+\alpha_{1} D_{i t}+\alpha_{2} \frac{R E_{i t}}{P_{t-1}}+\alpha_{3} D_{i t} \frac{R E_{i t}}{P_{t-1}}+\varepsilon_{i t}
$$

em que: Luc $_{\text {it }}=$ lucro líquido (contábil) por ação da empresa i no ano t; $D_{i t}=$ variável dummy será 1 se o retorno econômico for negativo e zero nos demais casos; $\mathrm{RE}_{\mathrm{it}}=$ retorno econômico por ação da empresa i no ano $t\left(P_{t}-P_{t-1}\right.$ ajustado pelo pagamento de dividendos); $\mathrm{P}_{\mathrm{t}-1}=$ preço da ação no final do ano anterior; $\alpha_{2}=$ reflete a oportunidade do lucro contábil, ou seja, o reconhecimento do retorno econômico pelo lucro contábil; $\alpha_{1}$ e $\alpha_{3}=$ refletem o reconhecimento assimétrico do retorno econômico, às boas e más notícias, pelo lucro contábil e $\varepsilon_{\text {it }}=$ termo de erro da regressão.

A utilização de uma variável dummy permite verificar, se o lucro contábil é mais sensível aos resultados negativos que aos positivos.

O coeficiente $\alpha_{2}$ captura o reconhecimento positivo e negativo, em conjunto, do retorno econômico pelo lucro contábil e o coeficiente $\alpha_{3}$ o resultado negativo, de acordo com as regras e práticas contábeis do país de origem da empresa $i$, permitindo a comparabilidade entre os países.

O coeficiente $\alpha_{2}$, ao refletir a oportunidade do lucro contábil no reconhecimento do retorno econômico, permite analisar a oportunidade da informação contábil (reconhecimento do retorno econômico pelo lucro contábil) na Argentina, no Brasil, na Colômbia, no Peru e na Venezuela, que é o primeiro objetivo deste trabalho.

Os coeficientes $\alpha_{1}$ e $\alpha_{3}$, são definidos como os coeficientes que refletem o reconhecimento assimétrico (Conservadorismo) do retorno econômico pelo lucro contábil. Esses coeficientes permitem atingir o segundo objetivo deste trabalho que é verificar se existem diferenças na aplicação do Conservadorismo (reconhecimento contábil dos resultados econômicos negativos e positivos), nos países estudados.

No estudo, se o lucro contábil incorporar mais significativamente o retorno econômico negativo

5 Penman e Zhang (1999) desenvolveram dois indicadores em seu trabalho. O $1^{\circ}$ denominado nível de aplicação do Conservadorismo pelas firmas, que tem a finalidade de mensurar o efeito do Conservadorismo no balanço - "C-scores". O $2^{\circ}$ denominado qualidade dos lucros, que resulta do efeito conjunto do Conservadorismo e da atividade de investimento - "Q-scores". 
que o retorno econômico como um todo, ou seja, se houver Conservadorismo no reconhecimento do retorno econômico pelo lucro contábil, é esperado que o coeficiente $\alpha_{3}$ seja maior e estatisticamente mais significativo que o coeficiente $\alpha_{2}$.

Para controle do efeito escala, as variáveis Lucro e Retorno econômico foram deflacionadas pelo preço da ação no final do período anterior $\left(\mathrm{P}_{t-1}\right)$, mesmo critério utilizado por Basu (1997).

As regressões foram rodadas utilizando a técnica de dados combinados. Combinando dados de séries temporal (dados do ano de 1995 a 2001) com dados de corte (todas as empresas com dados disponíveis no ano), será analisado o conjunto das regressões dos países nos anos de 1995 a 2001. Segundo Vinod e Ullah, citados por Gujarati (2000, p. 528), "a motivação básica para combinar dados de séries temporais e de corte é que, se o modelo está corretamente especificado, a combinação permite estimativa, inferência e, possivelmente, previsões de modo mais eficiente".

\subsection{Seleção da Amostra e Estatísticas Descritivas}

Os dados dos países para o estudo foram coletados do banco de dados do software Economática ${ }^{\circledR}$, no período de Dezembro de 1995 até Dezembro de 2001. Esse período foi escolhido devido, basicamente, à disponibilidade de dados.

As empresas que não possuíam dados disponíveis no ano para qualquer uma das variáveis foram eliminadas. Nas Tabelas 4 e 5, pode-se verificar, por país, o número de observações em cada ano do estudo, assim como as principais estatísticas descritivas das amostras; os dados primários são apresentados nos anexos ao trabalho.

Para reduzir o efeito dos extremos no resultado das regressões, foram eliminados da amostra $1 \%$ dos extremos superiores e inferiores em cada variável. Essa prática de eliminar 1\% dos extremos foi utilizada nos trabalhos de Basu (1997), Ball et al. (2000), Pope e Walker (1999) e Giner e Rees (2001).

Tabela 4 - Estatísticas Descritivas da Amostra

\begin{tabular}{|c|c|c|c|c|c|c|c|c|c|c|}
\hline & \multicolumn{2}{|c|}{ Argentina } & \multicolumn{2}{|c|}{ Brasil } & \multicolumn{2}{|c|}{ Colômbia } & \multicolumn{2}{|c|}{ Peru } & \multicolumn{2}{|c|}{ Venezuela } \\
\hline & Lucro & $\begin{array}{l}\text { Ret. } \\
\text { Econ. }\end{array}$ & Lucro & $\begin{array}{l}\text { Ret. } \\
\text { Econ. }\end{array}$ & Lucro & $\begin{array}{l}\text { Ret. } \\
\text { Econ. }\end{array}$ & Lucro & $\begin{array}{l}\text { Ret. } \\
\text { Econ. }\end{array}$ & Lucro & $\begin{array}{l}\text { Ret. } \\
\text { Econ. }\end{array}$ \\
\hline Média & 0,0200 & $(0,0118)$ & $(0,0391)$ & 0,2641 & 0,0735 & 0,1011 & 0,0710 & 0,0509 & 0,0607 & 0,3132 \\
\hline Mediana & 0,0458 & $(0,0428)$ & 0,1028 & 0,0532 & 0,1009 & 0,0214 & 0,0654 & 0,0101 & 0,0928 & 0,0364 \\
\hline Mínimo & $(1,2852)$ & $(0,7840)$ & $(11,929)$ & $(0,8026)$ & $(1,3312)$ & $(0,7386)$ & $(0,9934)$ & $(0,7579)$ & $(5,1036)$ & $(0,8417)$ \\
\hline Máximo & 0,5286 & 1,8627 & 3,4596 & 4,6861 & 2,2428 & 1,7755 & 1,1863 & 1,7890 & 0,9177 & 5,4548 \\
\hline $\begin{array}{l}\text { Desvio } \\
\text { Padrão }\end{array}$ & 0,2343 & 0,4172 & 1,0618 & 0,8386 & 0,3527 & 0,5144 & 0,2044 & 0,4517 & 0,6392 & 1,0001 \\
\hline N. Obs & \multicolumn{2}{|c|}{335} & \multicolumn{2}{|c|}{1882} & \multicolumn{2}{|c|}{153} & \multicolumn{2}{|c|}{464} & \multicolumn{2}{|c|}{149} \\
\hline
\end{tabular}

Tabela 5 - Distribuição da Amostra por Ano

\begin{tabular}{l|c|c|c|c|c|c|c}
\hline País/Ano & $\mathbf{1 9 9 5}$ & $\mathbf{1 9 9 6}$ & $\mathbf{1 9 9 7}$ & $\mathbf{1 9 9 8}$ & $\mathbf{1 9 9 9}$ & $\mathbf{2 0 0 0}$ & $\mathbf{2 0 0 1}$ \\
\hline Argentina & 43 & 50 & 53 & 54 & 50 & 46 & 39 \\
\hline Brasil & 519 & 265 & 261 & 233 & 298 & 318 & 288 \\
\hline Colômbia & 17 & 20 & 26 & 28 & 24 & 19 & 19 \\
\hline Peru & 68 & 80 & 77 & 69 & 68 & 54 & 48 \\
\hline Venezuela & 15 & 19 & 24 & 24 & 21 & 25 & 21 \\
\hline
\end{tabular}

\subsection{Resultados Encontrados}

O resultado da regressão será apresentado por país, assim como as estatísticas t para os coeficientes da regressão e o valor $p$. 
Tabela 6 - Resultados da Regressão Utilizando o Modelo de Basu (1997)

\begin{tabular}{|c|c|c|c|c|c|}
\hline \multicolumn{6}{|c|}{$\frac{\mathrm{Luc}_{\mathrm{itt}}}{\mathrm{P}_{\mathrm{t}-1}}=\alpha_{0}+\alpha_{1} \mathrm{D}_{\mathrm{it}}+\alpha_{2} \frac{\mathrm{RE}_{\mathrm{it}}}{\mathrm{P}_{\mathrm{t}-1}}+\alpha_{3} \mathrm{D}_{\mathrm{it}} \frac{\mathrm{RE}_{\mathrm{it}}}{\mathrm{P}_{\mathrm{t}-1}}+\varepsilon_{\mathrm{it}}$} \\
\hline & $\alpha_{0}$ & $\alpha_{1}$ & $\alpha_{2}$ & $\alpha_{3}$ & $\mathrm{R}^{2}$ Ajustado \\
\hline \multirow{2}{*}{ Argentina } & 0,07 & 0,07 & 0,04 & 0,53 & \multirow{2}{*}{0,176} \\
\hline & $(2,73)^{\star}$ & $(1,90)^{\star \star \star}$ & $(0,71)$ & $(5,51)^{\star}$ & \\
\hline \multirow{2}{*}{ Brasil } & 0,17 & $-0,13$ & $-0,1$ & 0,81 & \multirow{2}{*}{0,029} \\
\hline & $(3,82)^{\star}$ & $(-1,60)$ & $(-2,60)^{\star \star \star}$ & $(4,68)^{\star}$ & \\
\hline \multirow{2}{*}{ Colômbia } & 0,04 & 0,13 & 0,22 & 0,35 & \multirow{2}{*}{0,109} \\
\hline & $(0,76)$ & $(1,43)$ & $(2,65)^{\star}$ & $(1,61)$ & \\
\hline \multirow{2}{*}{ Peru } & 0,04 & 0,07 & 0,18 & 0,08 & \multirow{2}{*}{0,112} \\
\hline & $(2,07)^{\star \star}$ & $(2,34)^{\star \star}$ & $(4,87)^{\star}$ & $(1,17)$ & \\
\hline \multirow{2}{*}{ Venezuela } & 0,36 & $-0,29$ & $-0,25$ & 0,48 & \multirow{2}{*}{0,081} \\
\hline & $(3,86)^{\star}$ & $(-1,73)^{\star \star \star}$ & $(-3,67)^{*}$ & $(1,49)$ & \\
\hline
\end{tabular}

em que: *, ${ }^{* *},{ }^{* * *}$ - Estimativa significativa ao nível de 1\%; $5 \%$ e 10\% respectivamente; Estatísticas t para os coeficientes da regressão estão entre parênteses; Luc $_{\text {it }}=$ lucro líquido (contábil) por ação da empresa i no ano $t ; \mathrm{D}_{\mathrm{it}}=$ variável dummy será 1 se o retorno econômico for negativo e zero nos demais casos; $R E_{i t}=$ retorno econômico por ação da empresa i no ano $t\left(P_{t}-P_{t-1}\right.$ ajustado pelo pagamento de dividendos); $P_{t-1}=$ preço da ação no final do ano anterior; $\mathrm{a}_{2}=$ reflete a oportunidade do lucro contábil, ou seja, o reconhecimento do retorno econômico pelo lucro contábil; $\mathrm{a}_{1}$ e $\mathrm{a}_{3}=$ refletem o reconhecimento assimétrico do resultado econômico, as boas e más notícias, pelo lucro contábil e $e_{\text {it }}=$ termo de erro da regressão.

A Tabela 6 demonstra o resultado das regressões por país; o que se observa é que os sinais de $\alpha_{2}$ e $\alpha_{3}$ são positivos em praticamente todos os países, com exceção do $\alpha_{2}$ do Brasil e da Venezuela. O coeficiente $\alpha_{2}$ positivo revela uma relação direta entre lucro e retorno. Retorno positivo reflete lucro positivo e retorno negativo reflete lucro negativo. $O$ coeficiente $\alpha_{3}$ positivo demonstra que o retorno negativo multiplicado pelo intercepto positivo reflete no lucro negativamente, conforme esperado no modelo utilizado. Os resultados evidenciam que o valor $p$ e a estatística t em alguns interceptos não são significativos.

Quando se analisa se o modelo proposto explica a variação no lucro por meio da análise do $\mathrm{R}^{2}$ ajustado ${ }^{6}$, observa-se que os $\mathrm{R}^{2}$ ajustados variam de $2,9 \%$ a $17,6 \%$, conforme demonstrado no Gráfico 1 , sendo mais baixo no Brasil $-2,9 \%$ e mais alto na Argentina - 17,6\%. Quando se compara os $\mathrm{R}^{2}$ ajustados encontrados com os $\mathrm{R}^{2}$ ajustados do trabalho de Ball et al. (2000), em que países Codelaw apresentaram $\mathrm{R}^{2}$ ajustados variando de $4,2 \%$ a $12,6 \%$ e países Common-law $\mathrm{R}^{2}$ ajustado entre $9,1 \%$ e $17,0 \%$, percebe-se que os valores encontrados neste trabalho não diferem dos encontrados em outros países, com exceção da Argentina, onde é preciso estudar fatores internos do país para entender os resultados encontrados.

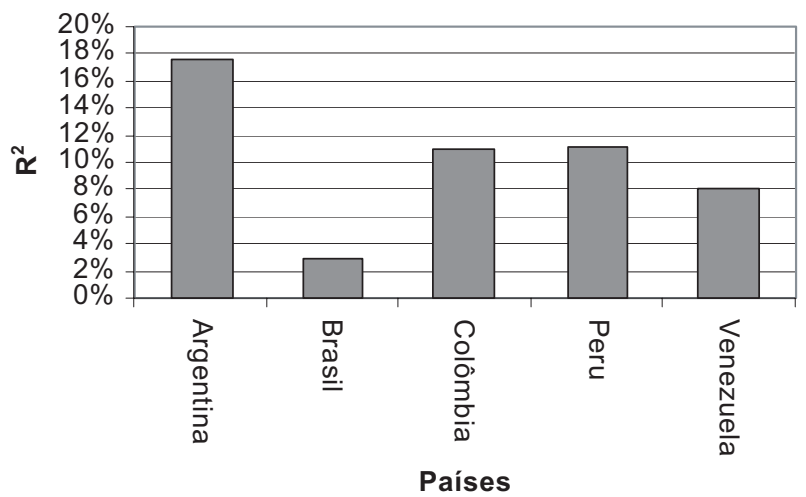

Gráfico $1-\mathbf{R}^{2}$ Ajustado

O Gráfico 2 demonstra o comportamento dos coeficientes das variáveis, retorno econômico e retorno econômico $\times$ dummy para cada país estudado, em que o coeficiente $\alpha_{3}$ é maior que o coeficiente $\alpha_{2}$, indicando um impacto maior do retorno negativo no lucro, do que do retorno como um todo, o que, conforme o modelo, é um indicador de Conservadorismo no reconhecimento de boas e más notícias pelo lucro contábil, em que apenas o Peru apresenta $\alpha_{2}$ maior que $\alpha_{3}$.

Observando a estatística descritiva do Brasil e da Venezuela, pode-se observar a razão para o 
$\alpha_{2}$ negativo nesses países, pois, enquanto a média do lucro é negativa ou tende para zero, a média do retorno econômico é positiva. No Brasil, enquanto o lucro varia de $(-11,93)$ a 3,46 com média de $(-0,04)$, o retorno varia de $(-0,80)$ a 4,69 com média de 0,26. $\mathrm{Na}$ Venezuela, o lucro varia de $(-5,10)$ a $0,92 \mathrm{com}$ média de 0,06 e o retorno varia de $(-0,84)$ a 5,45 com média de 0,31 .

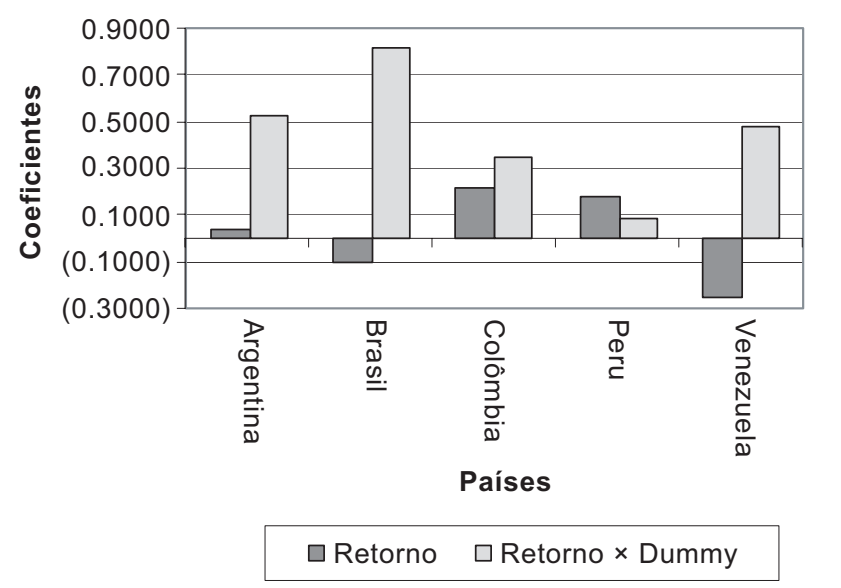

Gráfico 2 - Comportamento dos Coeficientes da Regressão

\section{CONCLUSÕES E SUGESTÕES PARA FUTURAS PESQUISAS}

Neste trabalho, procurou-se investigar a relação entre o lucro contábil e o retorno econômico em cinco países da América do Sul, ou seja, como o lucro contábil do período incorpora o retorno econômico corrente, assim como a assimetria nesse processo de reconhecimento de boas e más notícias. A base teórica é o modelo utilizado por Basu $(1997)$ que permite estudar as variáveis lucro, retorno, boas e más notícias.

Constatou-se, empiricamente, que um dos conceitos mais tradicionais da Contabilidade - Conservadorismo - está presente no processo de reconhecimento do retorno econômico pelo lucro contábil nos países estudados, membros de uma mesma região, a América do Sul e de dois blocos econômicos: a Comunidade Andina e o Mercosul. Dos resultados encontrados, neste trabalho, podem ser elaboradas algumas conclusões, em relação à capacidade do lucro contábil corrente refletir o retorno econômico corrente e a assimetria no reconhecimento dos resultados econômicos negativos e positivos.

Em linha com a literatura sobre o tema e com os resultados encontrados, pode-se observar a baixa relação entre lucro corrente e retorno corrente, resultado esperado em países Code-law, como os cinco estudados neste trabalho. Dessa forma, corroborando a literatura recente, que indica que nesses países, devido à relação entre modelos de governança corporativa e a relevância da informação contábil, em conjunto com o ambiente institucional dos países, a Contabilidade não incorpora, significativamente, o retorno econômico. Mesmo existindo baixa relação entre lucro corrente e retorno corrente, pode-se observar que o reconhecimento dos resultados negativos é maior que o reconhecimento do retorno como um todo, evidenciando Conservadorismo nos resultados contábeis.

O que se observa, nesses países, é que o principal foco da informação contábil não é o mercado de capitais, o que não quer dizer que a informação contábil não seja relevante, posto que a Contabilidade possui outros usuários e outros papéis. Nos países em desenvolvimento, como os cinco da amostra, a Contabilidade possui um importante papel de instrumento contratual entre as partes interessadas na empresa, quer seja entre acionistas, governo, credores e funcionários, diminuindo, dessa forma, conflitos e custo de transação.

Como sugestão para futuros estudos, nesse tema, poderia ser analisado qual o impacto da Governança Corporativa na utilização do Conservadorismo; se a necessidade das empresas reportarem em outra configuração contábil (USGAAP ou IFRS) impacta na utilização do Conservadorismo; se diferentes setores da economia utilizam o Conservadorismo de maneira diferente e ainda se o Conservadorismo é utilizado da mesma maneira, independente do tamanho da empresa, isto é, as empresas de grande porte utilizam o Conservadorismo da mesma forma que empresas médias ou pequenas. 


\section{REFERÊNCIAS BILBIOGRÁFICAS}

ALFORD, A.; JONES, J.; LEFTWICH, R.; ZMIJEWSKI, M.. The Relative Informativeness of Accounting Disclosures in Different Countries. Journal of Accounting Research, supplement to vol. 31, p. 183-223, 1993

ALI, A.; HWANG, L.. Country-Specific factors related to financial reporting and the value relevance of accounting data. Journal of Accounting Research, v. 38, n. 1, p. 1-21, Spring, 2000.

AMENÁBAR, A. M. H.. Harmonização Contábil em cinco países da América do Sul. 2001. Dissertação (Mestrado em Controladoria e Contabilidade) - Departamento de Contabilidade e Atuária, Faculdade de Economia, Administração e Contabilidade, Universidade de São Paulo, São Paulo.

BALL, R.; BROWN, S.. An Empirical Evaluation of Accounting Income Numbers. Journal of Accounting Research, vol. 6, pp. 159178, Autumn, 1968.

BALL, R.; KOTHARI, S. P.; ROBIN, A. The effect of international institutional factors on properties of accounting earnings. Journal of Accounting and Economics, vol. 29, pp. 1-51, 2000.

BASU, S.. The conservatism principle and the asymmetric timeliness of earnings. Journal of Accounting and Economics, n. 24, pp. 3-37, 1997.

BEAVER, W. The Information Content of Earnings Announcements. Empirical Research in Accounting: Selected Studies 1968 supplement to vol. 6 of Journal of Accounting Research, pp. 6792, 1968

; DEMSKI, J. S.. The Nature of Income Measurement. The Accounting Review, vol. XIV, pp. 39-53, January, 1979.

; LAMBERT, R; MORSE, D.. The information content of security prices. Journal of Accounting and Economics, 2, p.3$28,1980$.

CHAN, K.; CHAN, L. K. C.; JEGADEESH, N.; LAKONISHOK, J. Earnings Quality and Stock Returns: The evidence from Accruals. Jan. 2001. Disponível em: <http://papers.ssrn.com/ >. Acesso em: 14 fev. 2002.

GIL, A. C.. Como elaborar projetos de pesquisa. 3. ed. São Paulo: Atlas, 1991

GINER, B.; REES, W.. On the asymmetric recognition of good and bad news in France, Germany and the United Kingdom. Journal of Business Finance \& Accounting, p. 1285-1331, Nov./Dec. 2001.
GUJARATI, D. N.. Econometria Básica. 3. ed. Makron books: São Paulo, 2000.

HENDRIKSEN, E. S.; BREDA, M. F. V.. Teoria da contabilidade. Tradução de Antônio Z. Sanvicente, 5. ed. São Paulo: Atlas, 1999.

IASC. Framework for the Preparation and Presentation of Financial Statements. International Accounting Standards Committee. Londres: IASC, ed. anuais.

IUDÍCIBUS, S. Teoria da contabilidade. 6. ed. São Paulo: Atlas, 2000.

KOTHARI, S. P.; SLOAN, R. G.. Information in Prices About Future Earnings: Implications for Earnings Response Coefficients. Journal of Accounting and Economics, vol. 15, pp. 143-171, June-September 1992.

LA PORTA, R.; LOPES-DE-SILANES, F.; SHLEIFER, A.; VISHNY, R.. Law and Finance. The Journal of Political Economy, vol. 106, n. 6, pp. 1113-1155, 1998.

Investor Protection and Corporate Governance. Journal of Financial Economics, vol. 58, n. 1-2, pp. 3-27, Oct/Nov 2000.

LISBOA, N. P.. Harmonização de normas e práticas contábeis no Mercosul. 2000. Tese (Doutorado em Controladoria e Contabilidade) - Departamento de Contabilidade e Atuária, Faculdade de Economia, Administração e Contabilidade, Universidade de São Paulo, São Paulo.

LOPES, A. B.. Uma Contribuição ao Estudo da Relevância da Informação Contábil para o Mercado de Capitais: o Modelo de Ohlson Aplicado à BOVESPA. 2001. Tese (Doutorado em Controladoria e Contabilidade) - Departamento de Contabilidade e Atuária, Faculdade de Economia, Administração e Contabilidade, Universidade de São Paulo, São Paulo.

LUBBERINK, M.; HUIJGEN, C.. A Wealth Based Explanation for Earnings Conservatism. Nov. 2000. Disponível em: < http:// papers.ssrn.com />. Acesso em: 14 jun. 2002.

OHLSON, J. A.. Earnings, Book Values, and Dividends in Equity Valuation. Contemporary Accounting Research, v. 11, n. 2, p. 661-687, Spring 1995

PENMAN, H. S.; ZHANG, X.. Accounting conservatism, the Quality of Earnings, and Stock Returns. dez. 1999. Disponível em: <http://papers.ssrn.com/ >. Acesso em: 15 jan. 2002. 
POPE, P. F.; WALKER, M.. International Differences in the Timeliness, Conservatism and Classification of Earnings. Journal of Accounting Research, supplement to vol. 37, p. 503-87, 1999.

PORTELLA, G. R. O Conservadorismo e o Conteúdo Informativo dos Lucros. UnB Contábil - Departamento de Ciências Contábeis e Atuariais da Universidade de Brasília, Brasília, 1995.

PRICEWATERHOUSECOOPERS. Doing business and Investing in Brazil. PricewaterhouseCooper. São Paulo. 2001.

Doing business in Colombia. PricewaterhouseCooper. USA. 1993.

Doing business in Peru. PricewaterhouseCooper. USA. 1994.

. Doing business in Venezuela. PricewaterhouseCooper. USA. 1997
RICHARDSON, S.; SLOAN, R. G.; SOLIMAN, M.; TUNA, I.. Information in Accruals about the Quality of Earnings. jul. 2001. Disponível em: < http://papers.ssrn.com/> Acesso em: $14 \mathrm{fev}$. 2002.

WATTS, R. L.. A proposal for Research on Conservatism. Maio 1993. Disponível em: < http://papers.ssrn.com/ >. Acesso em: 14 jun. 2002.

WATTS, R. L.; ZIMMERMAN, J. L.. Positive Accounting Theory. New Jersey: Prentice-Hall, 1986.

WEFFORT, E.F.J. O Brasil e a Harmonização Contábil Internacional: Influências dos Sistemas Jurídico e Educacional, da Cultura e do Mercado. 2003. Tese (Doutorado em Controladoria e Contabilidade). Departamento de Contabilidade e Atuária da Faculdade de Economia, Administração e Contabilidade da Universidade de São Paulo, São Paulo.

\section{Endereço dos autores:}

FUCAPE

Av. Fernando Ferrari, 1358 - Goiabeiras

Vitória - ES

29075-010 